\title{
Investigation on illustration in urban advertising and its role in city image
}

Investigación sobre la ilustración en publicidad urbana y su papel en la imagen de la ciudad

Author:

Hanieh Eshaghzadeh Torbati ${ }^{*}$

\section{SCIENTIFIC RESEARCH}

How to cite this paper:

Eshaghzadeh Torbat H., Investigation on illustration in urban advertising and its role in city image, Iran. Innovaciencia 2020; 8 (1): 1 12. DOI : http :// dx .doi .org/10.15649/ 2346075X.1000

Reception date:

Received: 01 May 2020

Accepted: 01 August 2020

Published: 01 December 2020

Keywords:

Environmental Graphic; Illustration; Urban Advertising; Advertising Illustration, City Image.

\begin{abstract}
Illustration is a method used by graphic designers. Urban advertising is a subfield of environmental advertising (both of them are in environmental graphic) that in addition to the aspect of advertising, can affect on other aspects of city image. Indeed advertising illustration is generally an activity that an image is designed to advertise a product or special commodity. If this image located in the environment of city, becomes a part of urban advertising, and regarding to that today advertising exists everywhere. If the planning and management are not done properly in this regard, then it not only has a negative effect but also unintentionally causes to anarchy and lack of peace and comfort of residents. We aim to investigate on illustration in urban advertising and its role in city's image. Finally the article shows that the illustration on urban advertising is a method that can successfully act in regard to advertising and have a positive impact on urban image. Indeed attention and focus to the common aim should be considered.
\end{abstract}




\section{INTRODUCTION}

In the era of technology, according to busywork and speed of digital, the public has less time to read wide content of ads. In this situation, it seems necessary the conversion of writings, ads and information to visual forms, and illustrative images. Importance of illustration in advertising world appears more and more in the moment. The speed of transmission of message through image, especially in today's world, is become more important. In the world where visual media fills a large section of daily life of people and internet has converted the world to a small hamlet, it is felt more the need to an international and comprehensible language which can clearly speak. Illustration art not only in books, sites, and journals helps to express concepts and better understanding, but also has arrived to a position that can lonely be explored and perhaps it can explain concept together with information and advertising. Of course, a point should be considered that advertisements spread throughout the city, is very effective for city image and if they do not comply with the principles and criteria, then they will create adverse effects. While adhering to the principles and basses of proper designing not only reduces the crudities, ugliness, irregularities, and visual pollution of the city but also creates suitable spaces for residence and has a positive effect on city image.

Therefore it seems that illustration usage in advertising plays a role in beauty of city image such that citizenry feel comfort and understand them easily. Actually urban advertising uses different tools to full coverage in the city. In fact, urban advertising should be made its advertisements by applying the visual principles, the principles of engineering, and urban architecture. In other words, any advertising should have a positive impact on the city image in addition to the main purpose of showing a certain goal.

Applying analytical researches, we first study needed theoretical principles (basic and applied research) such as the environmental graphic, urban advertising, advertising illustration, and city image and then explain the illustration in urban advertising and its role on city image introducing and analyzing the infographic.

\section{1 main question of the research}

How can have a positive effect on city image by using illustration in urban advertising?

\section{BACKGROUND OF THE RESEARCH}

Different projects and articles are published about environmental graphic, environmental advertising, and urban advertising. However they have not studied the urban advertising that specially done by the illustration method and the method effect on city image. In the following, we refer the reader to some projects similar to our project:

1) The article „Investigation on environmental elements role in space visual quality " written by Asadolahi is published in 2010 in the seventh issue of Manzar Journal. The paper has studied environmental graphic, urban advertising, and place image, and after some explanations about applied areas of environmental graphic, it is studied urban advertising and finally has concluded generally. [1]

2) In 2014, Davdeh in the second national congress of architecture, restoration, urban engineering, and sustainable environment, in a research titled ,investigation on effect of graphic and environmental advertising on urban beauty" studied the concept of beauty and environmental graphic and then explained the effect of graphic on environment beauty. [2]

3) Ishagh zadeh and Sharifi in 2015 in the article ,investigation on role of urban advertisement in quality improvement of city image" pointed out that the quality and beauty of city image, along with urban advertising are very important. Actually applying the proper principles and regulations of design in the advertising, replacing, using the proper tools, and principally considering necessities and spatial qualities according to that (an important factor of making desirable urban space), can help to improve the quality of city image. Designers can improve this quality with careful decision making, with regard to 
the advertisement message, materials and tools, their location, and product features. [3]

4) In the book named as ,perception of city beauty and identity in the light of Islamic thought" by Naghi Zadeh in 2007, is mentioned that today, the cities of the old country (Iran) encounter with many issues and problems such as visual chaos, atonal appearance, lake of urban spaces which do not fit with national culture and identity and in other words they encounter with identity crisis. [4]

5) In the fourth issue of Chideman journal, in an article named as ,the position of environmental graphic in visual identity of city" by Mirzayi Nasab Fahadan, 2013, is attempted to study the position and importance of environmental graphic in improvement of visual identity of city by studying definitions related to urban identity and the role of urban design in making city identity. [5]

Robert Harland in his book (Graphic Design in Urban Environments) explained how graphic and communication design in the urban environment have been underrepresented or even ignored in graphic design historiography and in academic and educational definitions of the field, particularly in UK. He also effectively demonstrated the difficulties faced by urban theorists who try to describe the presence and relevance of graphic design artefacts in the public sphere, and the gaps and shortcomings of their approach. The careful descriptions and analysis presented in the book offer a framework for thinking about urban graphic interventions in multiple scales and settings. The result is a relevant contribution to design research, and should stimulate further and welcome debates on the interface between graphic design, communication, and urban design. [6]

The "Signage and Wayfinding" book in Chapter 1"What Is Environmental Graphic Design?" by Chris Calori David Vanden-Eynden in 2015, explains the contemporary incarnation of EGD (Environmental Graphic Design). EGD is a relatively new, cross-disciplinary field that has gained recognition and importance over the past forty years. EGD activity involves the development of a systematic, informationally cohesive, and visually unified graphic communication system for a given site within the built environment. [7]

An article, named as "A Study on the Characteristics of Visual Elements for Space Graphic Design" in Integrated Design Research Journal, is tried to study and investigate the characteristic of space graphic design through the analysis of its visual elements. By analyzing cases of actual usage, it enables to provide a basic visual system for space graphic design. In graphic within space, typography, colors, and light can be applied in complex form, in addition to basic modeling elements like the shape which forms the image. The expressive elements of graphic are displayed in the space form correlation and synthesize details to convey the identity.

In terms of the characteristics displayed through the analysis of design elements of space graphic, it includes a variety of expressions through artistic intervention, information communicability of typography, and expansion through optical illusion. Through this, artistic experience is provided for the subject of experience and sensible relations can be established. Successful space graphic design can form identify about place and community, and it can bring qualitative improvement in the urban environment through the acquisition of practical value. [8]

\section{BASIC AND PRACTICAL RESEARCHERS}

\section{1 environmental graphic}

Long before the invention of paper, humans made marks on objects. The intent of making these marks was to communicate information visually. This communication imbued these marks with meaning, and they became a shared language among the people who made and understood them. Environmental graphic design, or EGD, which can be defined as the graphic communication of information in the built environment, is one of the world's oldest professions. [9]

In western societies, graphics application in formation of internal spaces and urbanization are 
stated by term such as Environmental Graphic or Sign Design. If this application serves to external urban spaces such as streets, squares, green spaces, and external walls of buildings, then it is referred as City Signs (signs and urban or street graphic).

We all know common media applied in urban environmental graphic such as poster, signs, highway signs, road signs, fluorescent signs (neon), advertisings on vehicles, parks environmental design, design of buildings and resulted colors, public services spaces design, bus stops, phone booth, seats, environmental design of cultural and pleasure centers, design sculptures in squares and parks, or bas-relief of institutions and offices doorway, doorways panels of stores shops, cinemas and all public and private organizations and institutions, and different advertising panels, and also it is wellknown that graphic design is one of the messaging and advertising requirements in our life. Therefore acquaintance with culture of society and knowing its norms, values, customs, and regulations can be significantly important to environmental graphic design. As designer knows deeply about culture and moods of society people, he can easily establish simple and deep communication with audience through simple and clear express, and in simple words designer can return audience identity to him with the new express and different framework and in this way can speak to him.

Environmental graphic is a knowledge in which discussed and studied about how use different kinds of forms, colors, figures, and various pictures in a skillful, systematic, and planned way in order to making better and more simple relations, informing, and orientation, and also making beautiful the urban spaces such as public spaces. This knowledge is one of the most effective tools to affect on citizenships, and with visual design and relation it can return identity to audiences and seek to reform it based on components such as religion, rite, ethnicity, culture, customs and social contracts, economic and political trends and so on.

What is notable in environmental graphic is its role in shaping the face of city in structural relationship with identity body. Environmental graphic as a branch of graphic has an important role in reaching to distinctive goals and involves main part of commercial and promotional activities. Our surroundings, home where we live, street where we traffic, green space where we walk, park that we go there to fun, all need to making formal, logical, and exact organized relations based on principles and foundations of visual expression.

Actually human speaks to his environment and communicate with others through environmental graphic. Ibrahim Haghighi says that " graphic in urban area increases the level of people visual literacy and can organize city identity in order to citizen receives belonging sense to city according to himself identity, and even it undertakes the role of organizing and reconstruction in build and ancient spaces and can be designed for distinctive purposes.

\section{2 urban advertising}

Ilokhani in his book "environmental graphic" stated "regarding to that environmental graphic has broad sense and its definition includes a huge variety of visual elements, we can consider for it the history dating illustration" [10]. Indeed the history of urban advertising which is a branch of environmental advertising and placed in a subset of environmental graphic, is related to the first civilizations on earth. Generally all methods and tools which are used on stone columns in decorations on palaces and tombs of Egypt, inscriptions and petro glyphs of Achaemenid kings, and in promotion the religions of ancient Egyptians, are considered as a part of special environmental graphic of that time.

In 1800s many attempts were made to promote the quality of urban advertising which include using the projectors and shining light to the picture symbol specially the shops entrance signs. At the same time, many of shoppers in USA and Europe countries made bulk samples in large scale of their products. The bulks were placed on shops entrances and also placed by carts on the path of travel. In early of 1900s, it is observed the billboards which advertising of public goods, toiletries and the variety of drinks 
and snacks were installed on it. The trend was and is walking with accelerating progress of technology. As today we observe unique tools which can realize well initiatives and creativities of designers. Originally, as mentioned urban advertising as a branch of environmental advertising has an important role in promotion the culture and economy of any country. It also has the task of transmitting messages. Actually urban advertising is a way that can easily expose different messages to people such as the educational, cultural, social, economic, commercial and political. [1]

Urban advertising includes different tools and physical elements which are applicable in the body of city and is easily accessible for citizenships. Among them can refer to following cases:

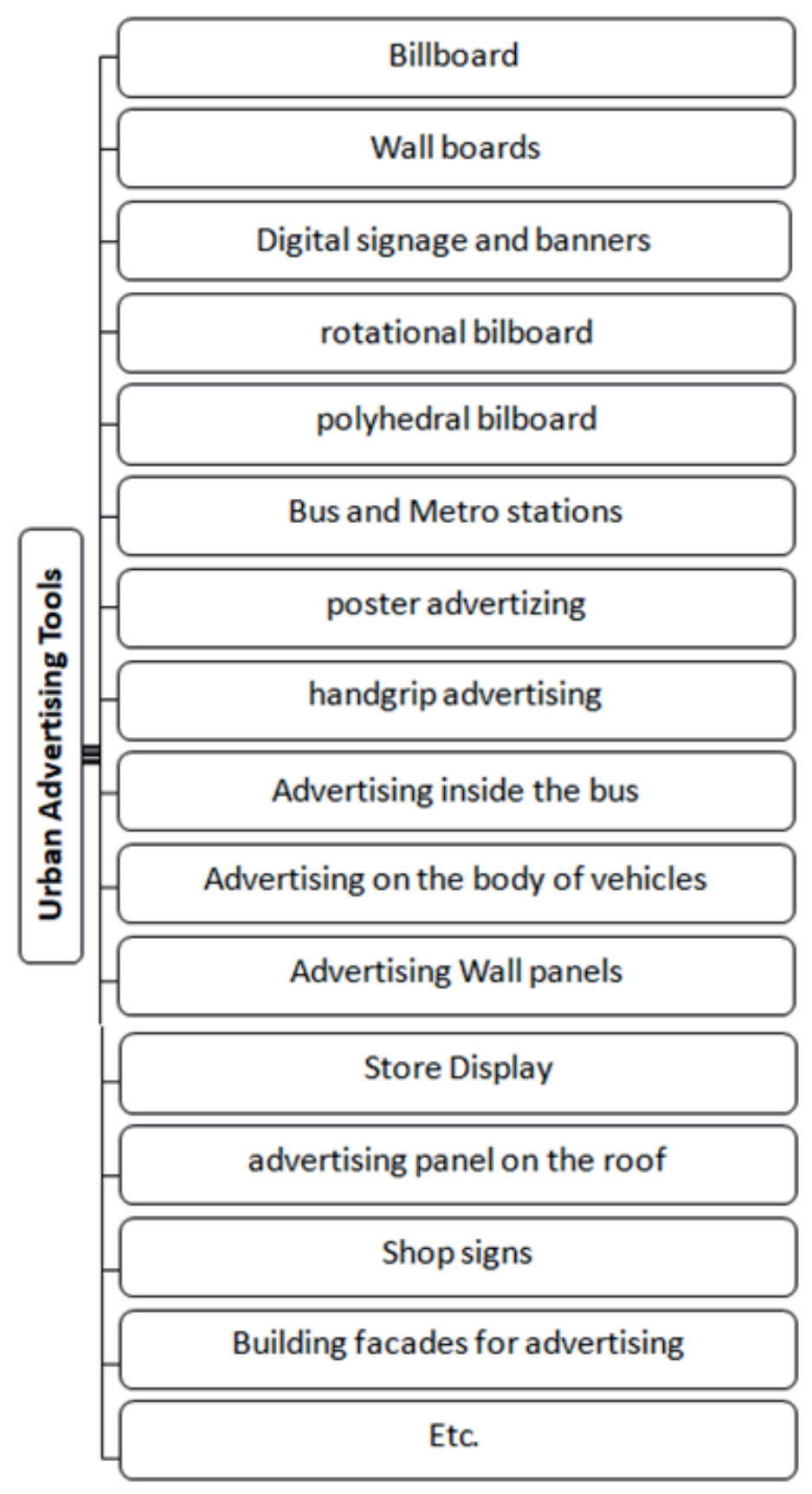

Infographic. 1. Urban Advertising Tools 
Due to stated materials, it is inferable that any kind of advertising in the urban space (open space) and in service and protective privacy that affects on urban image and its construct installation needs to municipal license, is considered as a part of urban advertising.

This kind of advertising is a media that there is everywhere with proper tools according to the environment and when combined with creativity, it makes new advertising environments which have not already been there. These environments can affect the people and use the distinction of full coverage in the city, and influence its contacts from earliest hours of the day until they are not in that environment.

\section{3 illustration}

The illustration is an art activity in which a picture is created to complement or induce a material. Indeed, it is a sub branch of graphic and designers can use it in different fields. The picture can be made to help the special comprehension, such as inducing special subject to viewer (advertising a product), designing a character for special purposes (mascot), or familiarizing the reader to story space or its heroes faces (book illustration) and having a completely decorative role and vice versa it is fully functional like scientific illustrations for educational books. The distinction between painting and illustration is inappreciable, and this differentiation of two is sometimes difficult. What is important is that techniques and tools do not differentiate the two cases but the designer purpose and the picture performance do it. Originally an illustrator should convey the message of sender to contact while a painter implements his feelings and usually the painting does not create for duplication. But the illustration is often made by an order and used for a special aim in the predicted number. An illustrator regarding to the customer order and by resort to his skills and art nature, presents a work that on one hand has lean characteristics of art work and on the other hand it induces its concept and purposes into viewer in some pictures. The illustration itself is divided in many subsets and has different kinds, due to the number and extent of illustration application in different social field. Different kinds of illustration are: press illustration (includes illustration for magazines and journals), illustration of book (includes illustration for story or scientificeducational subjects), and advertising illustration.

\subsubsection{Advertising illustration}

Generally, the advertising illustration is an activity in which is made a picture to advertise special product or commodity, perhaps "illustration for commercial advertising" can be used as an alternative for the word in the Persian language. [11]

The orientation of illustration has most dependency to its audience and viewer, because it should attracts viewers' attention, transfers its message to them, and finally attracts satisfaction of viewers for watching picture and encouraging them to buy commodity and services. The advertising illustration is formed by progress and development of illustration and then during the time as a new and independent art continues on his way for more development and progress. It can be said that today, generally the advertising illustration should have two main traits such as the visual logic and simplicity.

Simplicity is based on preserving open spaces in the picture and using solid and lifelike forms or forms which are seen soon, their identity is known, and their concept is easy to understand. An advertising illustration should focus on symbolic and compatible with each other appropriate concepts, but visual logic means "observe continuity" between different elements of every design and image. As the manifestation of supplied products, the presentation of idea and program, word or text with images, layout or composition of text, and an image which naturally is a part of illustration, all of the elements should support each other and confirm the main theme. [12]

\section{4 city image}

The term "city image" that often uses for Latin words" Image of the city", is actually processed an information in human mind and is the space that has role in the cognition and image of human. Social psychological factors such as the personal personality 
and personal and group experiences have a main role in urban image. [13]

In other words, the city image as an objective appearance of city is the most effective of urban indicators on human. Therefore, it is dependent on its audience. Because of the dependency of intellectual, environmental experiences, and mental memories of human, urban image is undeniable. Studies on the field of city image show that the human experience about urban spaces is the result of his present in an objective environment or in the body field. Therefore, the body image of city affects on two physical and mental dimensions of human in the urban environment. [14]

Mozayeni (translator of the book "image of the city") in the definition of image of city, explained that all factors of the city form the city image, which are observable and human eye can individually and specially see them when acts as continues and collectively (combination of some or several factors with each other in the moment). He referring to importance of city image, stated that in the today cities complex system, the pressure of city image is important as the pressure of air pollution and similar problems. Kevin Lynch, the writer of the mentioned book, assigned that five factors include the way, edge, knot, mark, and neighborhood as the main factors of city image. [15] As mentioned, different viewpoints and factors affect on making the city image. For example, some researchers know that the five elements of Lynch affect on forming the city image and they try to improve the quality of city image by improving these elements. Indeed creating the ideal city image in addition to space requirements and issue potentials needs to other qualities in space in order to place the space in the minds of citizenships (their mental image). [16]

Many tools and elements can affect on the qualities. For example, it can refer to the environmental graphic and in the following to the urban advertising. Colors and forms, which resort to any trick in order to being seen and forereach the rivals and as referred, play a significant role in the preservation and positive picture of city image. As Shiva stated that if urban graphic is not proper, then it makes people bad taste and if it is proper, it affects significantly on the visual culture of people and these show the effect of environment on audience.

Principally, existence of turbulent spaces destroys the beauty soul of cities. Of course, it should be mentioned that the satisfaction of citizen from city image doubtlessly in addition of their calm and efficiency, affects on making the interesting sense to their place. Therefore the city image in addition of art dimension is important in the psychological and social dimension.[17] Due to extensity, the urban advertising considered as an important factor in this regard that if done according to principles, affects positively on city image.

\section{INVESTIGATION ON ILLUSTRATION IN URBAN ADVERTISING}

In this age, the advertising job has had much advancement and now different companies and brands investigate that how they can use the intellectual advertising, so that it not only introduces products and services, but keeps in the mind of public that does not forget easily. Usually people do not have the patience to read texts and prefer to percept a picture using observation. Of course, the experience is shown that this method keeps more in mind of audience. The illustration uses as a method of using picture in the urban advertising and itself implemented by different techniques such as mascot designing, illustration with picture, illustration of product, illustration on picture, illustration by light, three dimensions painting, and so on. It is better that the advertising illustration implements, so that the product identity maintains and illustration implements in order to advertising are seen better, indeed it is powerful organizationally and beautifully.

The proper technique, exact character, beautiful colors, pleasant atmosphere, excellent composition, and so on can help the proper illustration.

The advertising illustration can get a help from different fields such as ceremonies (celebration days and ceremony days), urban special spaces, technology and so on to reach its goals. 


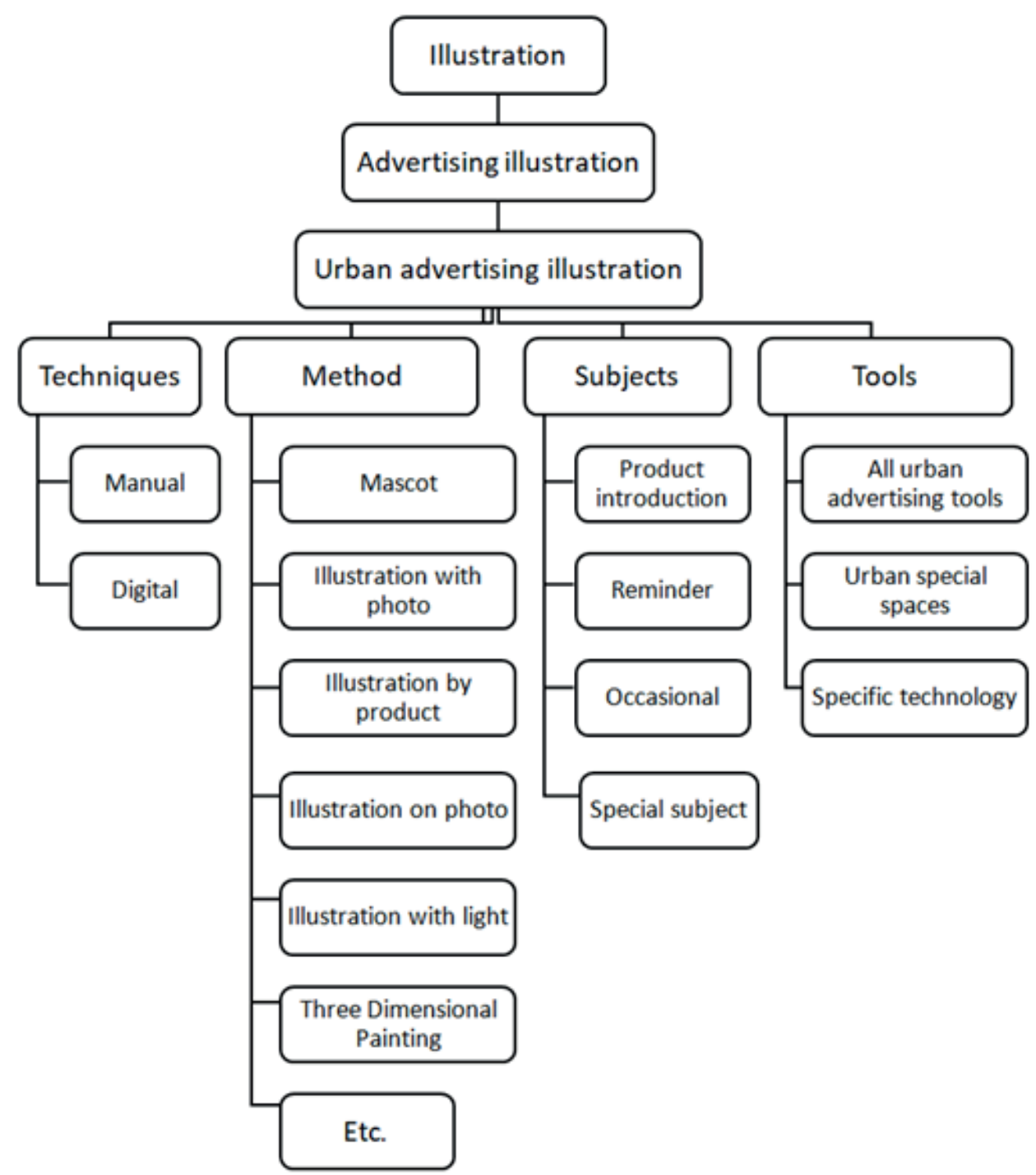

Infographic. 2. Illustration in Urban advertising

\section{ROLE OF ADVERTISING ILLUSTRATION IN CITY IMAGE}

All factors which are seen from city and are observable by human eye, can considered as a part of city image. Therefore, the urban advertising is considered as a part of city image and as before mentioned, the illustration is one of the methods that is used by designers in the urban advertising. As usually when advertising, paid attention to advertising aim, most of the times beauty and coordination with environment, illustrative pollution, city identity, and so on are ignored and the cases are very effective on the city image.

Since designing by illustration has much ability to correlation with environment and is a popular and proper method in the urban advertising, we can use it as a mutual method that is paid attention to its impact on the city image and also the advertising (main aim of advertising). In other words, cases such as spatial requirements (spaces need to different cases such as light, green space, city furniture and etc.) and spatial qualities (variety, readability, permeability, accessibility, convenience, security, repose, animation, diversity and etc.), that affect on creating desirable urban space and consequently on the quality of city image, should be of great attention. Indeed since the effectiveness of advertising on city image is undeniable, it can be a method to make a better city image and be a way to remove visual pollutions from the city, and if this principle alongside visual 
basics principles, urban engineering and architecture regulations, maintain of city identity and aesthetics, will be successful. In infographic 3, it has tried to show the relation aim. between different environmental designs, specially advertising to city image. Actually when there is a common purpose, the elements will be able to effective to the common aim in addition to the main

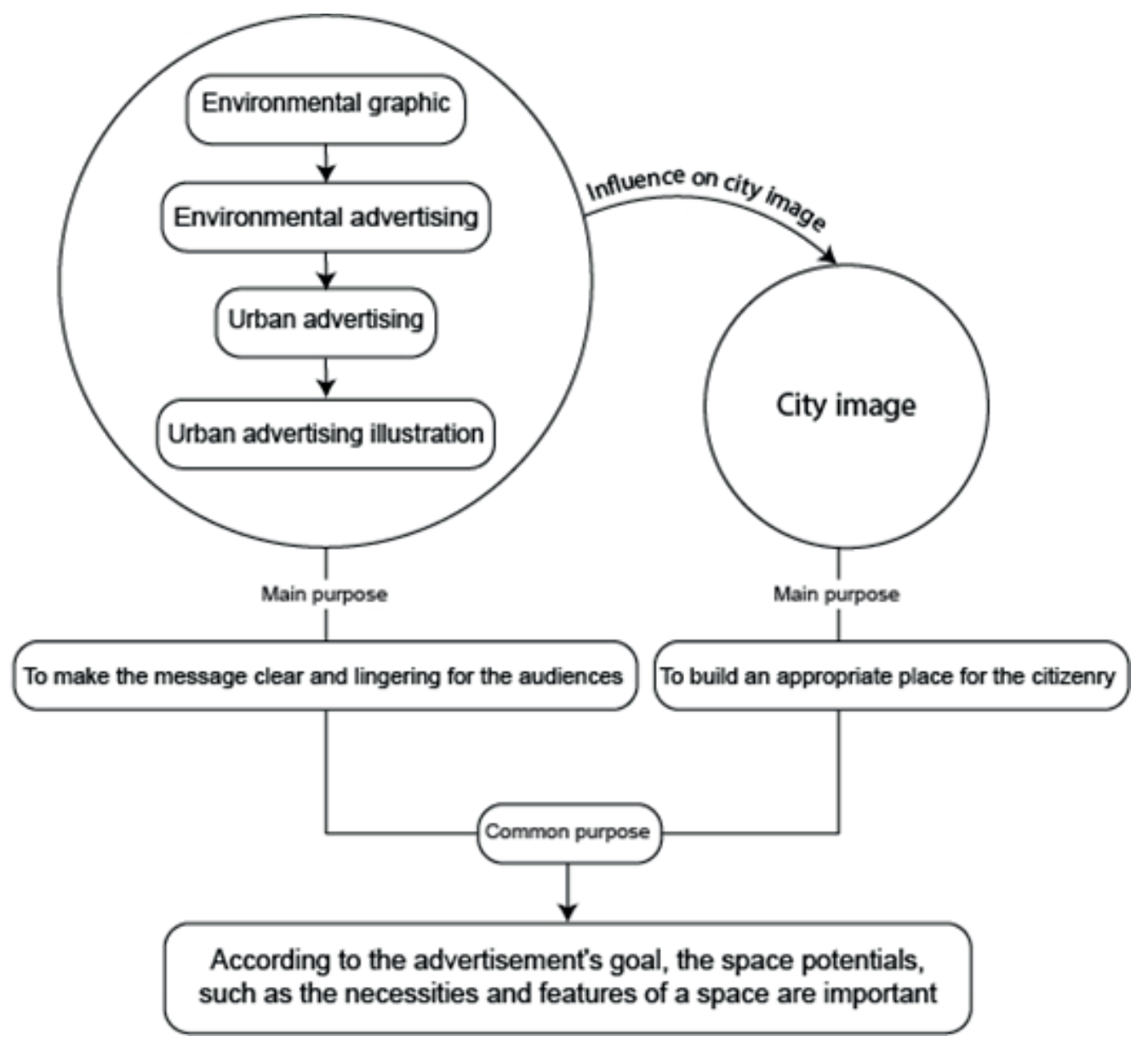

Infographic. 3. Common purpose in urban advertising and city image

\section{SUMMARY AND CONCLUSION}

As the environmental graphic being a knowledge with different functions (advertising, educational, leading and guidance, fancy), can help significantly to cities design. A case is that it can positively affect on the city image in addition on its function. The case can have most importance in create the health environment for living human. Hence designers, authorities, and experts should design it, so that the life and living conditions in it have necessary logic and beauty.

Today, world cities are full of signs, marks, and other instructor and informer graphic elements which are cause of order and help to managers and executors to execute regulations and considered as economic development tools. Important cities of the world are competing with each other for business and tourism and are finding ways and more attractive and obvious marks in order to guidance and attract attention of visitors. Yet every year many buildings and centers in the world are made which due to similar reasons provide newer and more creative environmental graphic. Traffic signs, video and text navigation systems for private and public places, commercial ads and dozens of other cases play an important and unassailable role in the service delivery, guidance, facilitate the traffic and urban transport and information. Designers of environmental graphic 
can active along with architectures, planners and other agents involved in designing and building the urban environments in order to organize the environmental graphic elements. Environmental graphic elements ought to using of aesthetic and psychology aspects are designed and created, so that they cause to calm, repose, happy, tolerance and, persistence in today industrial environments and mechanical life in addition to having the proper quality in the function and service delivery. [1]

The environmental graphic is executable by different tools and methods. The advertising illustration is a method which is used by designers in urban advertisement. Generally, in advertisement, a designer firstly notices to sending a message to audience and even efforts to make a memory for audience, so that it keeps in his mind. A designer acts similarly in an advertising illustration and when creating a picture, pays all his attention to the purpose of advertising. But the important point is that an advertising is a component of elements which form the image of city, and if it is considered only the main purpose, it will make some problems for residents, for this reason, potentials of urban space (necessities and qualities) should be recognized and designs be done according to need and identity of city and citizenship. Of course it should not be forgotten that the advertising regarding to their success, needs to investor satisfaction and supplies the needs of their audience. Originally drawing attention and targeting of audiences are very important in urban advertising; however it is better to paid an attention to the advertisement and city image by having a common purpose. Therefore it will create a positive effect on city image. Indeed due to that, the urban advertising is a component of city elements that can increase or decrease visual literacy of people, and it plays the role of beautification or confounding and in general has different effects on its audiences. Designers due to the message of advertising, materials and tools, its position and by considering clear characteristics of product can step in this way with a little thought and wisdom and actually introduce illustration of their advertisement to audiences due to the importance of city image for residents.

\section{REFERENCES}

1. M. Asadollahi (2010).'Investigation on environmental elements in space visual quality", Manzar journal, n 70.7

2. S. Davdeh (2014), "investigation on impact of graphic and environmental advertising on urban beauty", second congress of architecture, urban engineering and constant environment, Hamadan, Iran, October 4.

3. H. Ishagh Zadeh Torbati and A. Sharifi Noghaby, (2015), "Investigation on the role of urban advertising in improvement of city image quality", third international congress of development, architecture and urban development, Tehran, Iran, December 29-31.

4. M. Naghizadeh (2007), "percept the beauty and identity of city in light of Islamic thought", entertaining -cultural organization of Isfahan municipality. Isfahan.

5. M. Mirzayi Nasab Fahadan,(2013), "the position of environmental graphic in city visual identity", Chideman, second year, number 4, Tehran, winter.

6. Harland, Robert. "Graphic Design in Urban Environments" (October 20, 2016). Doi: 10.5040/9781472597786.

7. Calori, Chris, and David Vanden Eynden. "Signage and Wayfinding Design: A Complete Guide to Creating Environmental"(June 30, 2015). Doi: 10.1002/9781119174615.

8. Sur, Yeonwha. "A Study on the Characteristics of Visual Elements for Space Graphic Design." Integrated Design Research (Jun 2013): 45 to 56. doi:10.21195/jidr.2013.12.2.004.

9. Calori, Chris, and David Vanden Eynden. "Signage and Wayfinding Design: A Complete Guide to Creating Environmental"(June 30, 2015). Doi: 10.1002/9781119174615.

10.M. Ilokhani (2009), "environmental graphic", Fatemi publication", Tehran.

11. P. Esfandi (2004), “advertising illustration", journal of visual arts studies, number 21, 34-41.

12. Feldman, B. L. and Gross, J. (1999). "Discrete emotions or dimensions? The role of valence focus and arousal focus". Journal of Cognition and Emotion. Vol. 19, No.12: 72- 79.

13.J. Pakzad (2009), "theoretical foundations and urban designing process", first edition, Shahidi Publication, Tehran. 
14. N. Zibayi and R.Rezazadeh. (2010), "investigation on the relation between visual image of Tehran city areas and citizens behavior", periodical urban management studies, second year, number 1.

15. K. Lynch (2013)," image of the city" translated by Mozayeni, Manoochehr, nine edition, Tehran University publications, Tehran.
16. N. Manoochehri, M. Hedayati and M. Fallah (2013), "the role of urban furniture designing in giving identity to city image", first national conference of architecture and constant urban spaces, Mashhad.

17.A. Nazariyan, K. Zalnegad and SH. Irani (2013), "urban furniture, problems and challenges", Tehran, university press publications. 
12 Innovaciencia 